\title{
Hypoxia, nitrogen balance and body weight
}

\author{
A.M.W.J. Schols*, K.R. Westerterp\#
}

Recent clinical studies have shown that acute exacerbations of chronic obstructive pulmonary disease (COPD) are characterised by disturbances in the balance between dietary intake and energy expenditure $[1,2]$ as well as by a negative nitrogen balance [3]. Since weight loss prior to and during hospitalisation for an acute exacerbation has been related to poor outcome in terms of mortality and readmission rate $[4,5]$, it is important to prevent or treat this complication. It is yet unclear to what extent factors contributing to weight loss, during acute disease exacerbations, are similar to stable disease. Elevated energy requirement of physical activity has been implicated during stable disease [6] but is unlikely to be an important factor during acute disease, when the activity level is probably very low. Hypoxia is otherwise implicated as a potential trigger of reduced dietary intake and metabolic alterations during acute exacerbations, while in stable disease, there is no strong relationship between resting arterial oxygen tension and nutritional status.

Hypobaric hypoxia, as applied in high-altitude studies, clearly induces weight loss and is an interesting human model to investigate the influence of acute hypoxia. There is evidence that the altitude limit for the maintenance of body weight in humans is $\sim 5,000 \mathrm{~m}$ [7]. Acute transfer from sea level to altitude usually results in weight loss, but the rate of weight loss diminishes when the food supply is adequate. Reduced dietary intake is initially the result of a reduced meal size because of a rapid increase in satiety during the meal [8]. Part of the effect of reduced meal size on daily dietary intake can be compensated for by an increase in meal frequency. At altitudes of $\geqslant 7,000 \mathrm{~m}$, acute mountain symptoms result in suppression of hunger and the desire to eat [8], possibly related to a reduction in appetite through leptin, a key mediator in the neuroendocrine regulation of food intake [9]. The effect of hypobaric hypoxia on resting metabolic rate is unclear. High-altitude studies are limited by the fact that subjects are often highly trained and have a physical activity related energy expenditure that is comparable to that of endurance athletes. A more specific study on nitrogen balance during a prolonged stay at $5,000 \mathrm{~m}$ showed no impairment of protein digestibility

Depts of *Pulmonology and ${ }^{*}$ Human Biology, Maastricht University, Maastricht, the Netherlands.

Correspondence: A.M.W.J. Schols, Dept of Pulmonology, University Hospital Maastricht, P.O. Box 5800, 6202 AZ Maastricht, the Netherlands. Fax: 31 433875051.E-mail: a.schols@pul.unimaas.nl
[10]. However, glycine metabolism, as measured with glycine $\left({ }^{15} \mathrm{~N}\right)$, changed as a function of altitude exposure. Urinary excretion of ${ }^{15} \mathrm{~N}$ from intravenous glycine administration, as a fraction of urinary nitrogen, increased from $20.6 \%$ after 4 days to $38.0 \%$ after 13 days at altitude $(\mathrm{p}<0.05)$. It was hypothesised that the increased ${ }^{15} \mathrm{~N}$ excretion was due to increased oxidation of glycine as a function of altitude exposure. Others have also observed an altitude-induced increase in capillary leakage resulting in a renal loss of amino acids [11].

Experimental models subjecting animals to a hypoxic environment, i.e. that of IIOKA et al. [12] in the current issue of this journal, are comparable to an altitude of $5,000 \mathrm{~m}$ with regards to the hypoxia created. To avoid effects of hypoxia-induced hypophagia, the rats studied were given total parenteral nutrition (TPN). Nevertheless, exposure to hypoxia caused a negative nitrogen balance, which was mainly due to increased urinary nitrogen excretion. A reduction in oxygen availability, especially in the acute situation, probably results in a reduction of physical activity. Reduction of physical activity diminishes the need for proteins and/or results in short-term muscle atrophy. The observed reduction in the net-nitrogen retention in the rats during acute hypoxia, as reflected by the increased levels of urinary nitrogen loss, could be an effect of "detraining". In a previous issue of this journal, Pison et al. [13] described the effect of hypoxia on intermediary metabolism. They used a comparable rat model that was standardised for marked hypophagia, by investigating the effects of acute starvation. They reported that, in contrast to hypercatabolic states, hypoxia did not affect amino-acid adaptation to starvation. However, they also observed insulin resistance and reduced lipolysis. These metabolic adaptations point towards the potential adverse effects of metabolic overload by hyperalimentation under such hypoxic circumstances.

The study of IIOKA et al. [12] shows that rh insulinlike growth factor (rhIGF-1) can prevent the acute net catabolic effect of hypoxia, as reflected in a negative nitrogen balance, but that compared to normoxic conditions, weight gain is less pronounced. A combined therapeutic approach of both nutritional support and IGF was needed to induce a net anabolic effect. The authors suggest that further studies are warranted to determine whether an intervention consisting of TPN and rhIGF-1 can be applied to the setting of acute exacerbation with hypoxaemia for chronic respiratory disease. Although 
this is a tempting option, it is very difficult to translate "straight forward" experimental models to complex and heterogeneous conditions like acute exacerbations. Conversely, the charm of the model in terms of timing and type of nutritional support limits extrapolation. Clinical management of acute hypoxic exacerbations will primarily be directed to reverse hypoxia. VERMEEREN et al. [1] reported that after normalisation of arterial blood gases, dietary intake generally improves spontaneously. It is as yet unclear whether a positive energy balance can be reached in patients that remain hypoxic by oral nutritional support per se. TPN is not a common modality in respiratory disease. The gastrointestinal tract is generally intact and enteral nutrition outweighs both costs and risks of TPN. However, besides the observed effects under hypoxic condition, there are other arguments for considering rhIGF-1 treatment during acute exacerbations. Medical treatment of acute exacerbations commonly includes high-dose systemic glucocorticoids. SAudny-Unterberger et al. [3] showed that the severity of a negative nitrogen balance during acute exacerbations of COPD is associated with systemic glucocorticoids in a dose-dependent fashion. Acute treatment with high-dose glucorticosteroids decreases IGF-1 and IGF-2 expression in the rat diaphragm and gastrocnemius [14]. In vitro and experimental studies have shown that IGF treatment can reverse detrimental effects of corticosteroid-induced muscle wasting $[15,16]$.

Further clinical studies are warranted to investigate whether insulin-like growth factor-1 may also be of value for offsetting adverse effects of glucocorticoids in the short-term, as observed during acute exacerbations.

\section{References}

1. Vermeeren MA, Schols AM, Wouters EF. Effects of an acute exacerbation on nutritional and metabolic profile of patients with COPD. Eur Respir J 1997; 10: 2264-2269.

2. Creutzberg EC, Wouters EFM, vanderHoven-Augustin IML, Dentener MA, Schols AMWJ. Disturbances in leptin metabolism are related to energy imbalance during acute exacerbations of chronic obstructive pulmonary disease. Am J Respir Crit Care Med 2000; 162: 1239-1245.

3. Saudny-Unterberger H, Martin JG, Gray-Donald K. Impact of nutritional support on functional status during an acute exacerbation of chronic obstructive pulmonary disease. Am J Respir Crit Care Med 1997; 156: 794-799.

4. Connors AF, Dawson NV, Thomas C, et al. Outcomes following acute exacerbation of severe chronic obstructive lung disease. Am J Respir Crit Care Med 1996; 154: 959-967.

5. Pouw EM, Ten Velde GP, Croonen BH, Kester AD, Schols AM, Wouters EF. Early non-elective readmission for chronic obstructive pulmonary disease is associated with weight loss. Clin Nutr 2000; 19: 95-99.

6. Baarends EM, Schols AM, Pannemans DL, Westerterp KR, Wouters EF. Total free living energy expenditure in patients with severe chronic obstructive pulmonary disease. Am J Respir Crit Care Med 1997; 155: 549554.

7. Westerterp KR. Energy and water balance at high altitude. News Physiol Sci 2001; 16: 134-137.

8. Westerterp-Plantinga MS, Westerterp KR, Rubbens M, et al. Appetite at 'high altitude' (Operation Everest III (Comex-'97)): a simulated ascent of Mount Everest. J Appl Physiol 1999; 87: 391-399.

9. Tschop M, Strasburger CJ, Hartmann G, Biollaz J, Bartsch P. Raised leptin concentrations at high altitude associated with loss of appetite. Lancet 1998; 352: 1119-1120.

10. Kayser B, Acheson K, Decombaz J, Fern E, Cerretelli P. Protein absorption and energy digestibility at high altitude. J Appl Physiol 1992; 73: 2425-2431.

11. Lewis DM, Bradwell AR, Shore AC, Beaman M, Tooke JE. Capillary filtration coefficient and urinary albumin leak at altitude. Eur J Clin Invest 1997; 27: 64-68.

12. Iioka Y, Tatsumi K, Sugito K, Moriya T, Kuriyama $\mathrm{T}$. Effects of insulin-like growth factor on nitrogen balance during hypoxic exposure. Eur Respir J 2002; 20: 293-299.

13. Pison $\mathrm{CM}$, Chauvin $\mathrm{C}$, Perrault $\mathrm{H}$, et al. In vivo hypoxic exposure impairs metabolic adaptations to a 48 hour fast in rats. Eur Respir $J$ 1998; 12: 658-665.

14. Gayan-Ramirez G, Vanderhoydonc F, Verhoeven G, Decramer M. Acute treatment with corticosteroids decreases IGF-1 and IGF-2 expression in the rat diaphragm and gastrocnemius. Am J Respir Crit Care Med 1999; 159: 283-289.

15. Kimura K, Kanda F, Okuda S, Chihara K. Insulinlike growth factor 1 inhibits glucocorticoid-induced glutamine synthetase activity in cultured L6 rat skeletal muscle cells. Neurosci Lett 2001; 302: 154 156.

16. Kanda F, Takatani K, Okuda S, Matsushita T, Chihara K. Preventive effects of insulinlike growth factor-I on steroid-induced muscle atrophy. Muscle Nerve 1999; 22: 213-217. 